\section{Decaimento bacteriano em lagoas de polimento tratando efluentes de reator UASB}

\section{Bacterial decay in polishing ponds treating UASB reactor effluents}

Mariana Medeiros Batista' | George Rodrigues Lambais² | Silvânia Lucas dos Santos ${ }^{3}$ | Adrianus van Haandel ${ }^{4 *}$

ORCID ID

Batista MM (D) https://orcid.org/0000-0002-4492-8543

Lambais GR (ID) https://orcid.org/0000-0001-9141-7466
Santos SL (DD https://orcid.org/0000-0002-6905-3966

Haandel A (18) https://orcid.org/0000-0002-9937-6715

\title{
Resumo
}

Este estudo objetivou desenvolver expressões para determinar o valor da constante de decaimento em lagoas de polimento tratando efluente de reator UASB em função da profundidade da lagoa e da temperatura, bem como avaliou a influência do regime hidráulico sobre a eficiência da remoção bacteriana, visando estimar o tempo de permanência necessário para obter um efluente com qualidade higiênica para uso na irrigação irrestrita. A remoção bacteriana foi avaliada, em termos de E.coli, em 06 lagoas com profundidades variando entre 0,2 a 2,8 m. Pôde-se verificar que a constante de decaimento variou de modo inversamente proporcional à profundidade das lagoas. Além disso, o decaimento bacteriano se desenvolveu, em boa aproximação, conforme um processo de primeira ordem, tendo, portanto, uma vantagem considerável nas unidades operadas em regime de bateladas sequenciais (onde o decaimento é inversamente exponencial) sobre as lagoas de fluxo contínuo (onde o decaimento é inversamente hiperbólico).

Palavras-chave: Tratamento de esgoto. Qualidade higiênica. Coliformes Termotolerantes. Cinética de decaimento.

\section{Abstract}

This study aimed to develop expressions for the value of the decay constant in polishing ponds as a function of pond depth and temperature, as well as to evaluate the influence of the hydraulic regime on the efficiency of bacterial removal in order to estimate the residence time necessary to obtain a hygienic quality effluent for unrestricted irrigation. The bacterial removal was evaluated, in terms of E.coli, in 06 ponds operating with depths between 0.2 to 2.8. It was possible to verify that the decay constant varies inversely proportional to the depth of the ponds. In addition, the bacterial decay in units in good approximation developed as a first order process, so that ponds with a sequential batch regime (having exponential decay) have a considerable advantage over the continuous flow pond (with a inversely hyperbolic decay).

Keywords: Sewage treatment. Hygienic quality. Thermotolerant Coliforms. Decay kinetics.

\footnotetext{
${ }^{1}$ Universidade Federal do Amazonas - UFAM - Itacoatiara - Amazonas - Brasil

2 Instituto Nacional do Semiárido - INSA - Campina Grande - Paraíba - Brasil.

${ }^{3}$ Universidade Federal do Rio Grande do Norte - UFRN - Natal - Rio Grande do Norte - Brasil.

${ }^{4}$ Universidade Federal de Campina Grande - UFCG - Campina Grande - Paraíba - Brasil.

* Autor correspondente: adrianusvhagmail.com.
} 


\section{INTRODUÇÃO}

Em localidades que apresentam déficits hídricos, a água constitui um elemento limitante para o desenvolvimento de diversas atividades humanas, inclusive para a agricultura e indústria. Nessas condições, a busca por fontes alternativas desse recurso se torna uma necessidade (HESPANHOL, 2002). O esgoto doméstico constitui uma fonte de água não convencional e contínua e, caso seja coletado e tratado de forma adequada, pode satisfazer uma parcela importante dessa demanda. Ao mesmo tempo, a aplicação de esgoto tratado como água de irrigação contribui substancialmente para a redução dos impactos ambientais, como a poluição orgânica e a eutrofização dos corpos d'água. $O$ tratamento de esgoto para uso agrícola tem dois objetivos principais: (1) redução da concentração de material orgânico, normalmente representado em termos de Demanda Bioquímica de Oxigênio - DBO, para evitar o desenvolvimento da digestão anaeróbia e o crescimento de biomassa bacteriana no sistema de irrigação; e (2) a redução da concentração de organismos patogênicos, cuja presença prejudica tanto os trabaIhadores que manipulam a água como a qualidade higiênica dos produtos agrícolas, especialmente aqueles que são consumidos crus.

A irrigação de diferentes culturas agrícolas, inclusive de hortaliças consumidas cruas, é amplamente aplicada, especialmente em regiões de clima árido e semiárido (HETTIARACHCHI; REZA ARDAKANIAN, 2016; LEAL et al., 2011; PEDRERO et al., 2010). A Organização Mundial de Saúde (WHO, 2006) estabelece recomendações sanitárias para uso de esgoto na agricultura irrestrita baseada em dois tipos de organismos indicadores de contaminação fecal: Escherichia Coli, pertencente às bactérias do grupo coliformes, cuja concentração não pode exceder o valor de $10^{3} \mathrm{E}$. Coli por $100 \mathrm{~mL}$ de água, e ovos de helmintos, cuja concentração não pode exceder 1 ovo viável por litro (L) de água. Na prática, a remoção de ovos de helmintos é mais rápida e requer a aplicação de processos físicos, como a sedimentação (CAVALCANTI, 2003; NELSON et al., 2004). Já a remoção de bactérias, como a Escherichia Coli, pode ocorrer por diferentes mecanismos, sejam eles químicos (desinfetantes, $\mathrm{pH}$, oxigênio dissolvido), físicos (radiação UV, temperatura, sedimentação) ou biológicos (predação, competição, decaimento bacteriano natural) (LIU; HALL; CHAMPAGNE, 2018), combinados ou não entre si.

Em países com clima quente, a combinação de reatores anaeróbios de fluxo ascendente e manta de lodo (UASB) com lagoas de polimento é considerada uma opção atraente para o tratamento de efluentes domésticos devido, dentre outros aspectos, à simplicidade, ao baixo custo e à robustez dessas unidades (VAN HAANDEL; LETTIN$G A, 1994)$. Os reatores UASB são unidades que contribuem de forma considerável para a redução do material orgânico (remoção de 70 a $80 \%$ da DBO) e de organismos patogênicos (remoção de 90\% dos Coliformes Termotolerantes - CTT) nos esgotos domésticos (CAVALCANTI, 2003), embora isso não seja suficiente para produzir uma água com características adequadas para uso na agricultura.

Lagoas de polimento podem ser utilizadas como unidades de pós-tratamento com a finalidade de adequar a qualidade do efluente de reatores UASB para uso agrícola, aumentando a eficiência de remoção da DBO e bacteriana e, ao mesmo tempo, removendo quase completamente os ovos de helmintos, produzindo assim uma água para irrigação sem restrições e com os nutrientes do esgoto preservados.

Estudo realizado por Cavalcanti (2003) mostrou que o tempo de permanência para remover os CTT em lagoas de polimento é muito maior que o tempo para remover ovos de helmintos e a DBO, por isso a remoção bacteriana passa a ser o mecanismo que define o tempo de permanência mínimo e, portanto, as dimensões de lagoas de polimento. 


\subsection{Cinética do Decaimento de Coliformes Termotolerantes}

A cinética da desinfecção está baseada na Lei de Chick (CHICK, 1908), segundo a qual o decaimento bacteriano é descrito como um processo de $1^{\mathrm{a}}$ ordem, em que a taxa de redução de uma determinada população de bactérias é proporcional à sua concentração inicial. Essa relação foi também encontrada por Marais e Shaw (1961) em estudos baseados no decaimento de coliformes termotolerantes (CTT) em lagoas de estabilização, sendo representada pela Eq. 1.

$$
r_{d}=\frac{d N}{d t}=-k_{b} N
$$

Em que:

$r_{d}=$ taxa de decaimento dos CTT;

$\mathrm{t}=$ tempo (dia);

$\mathrm{N}$ = número de CTT (UFC/100mL);

$k_{b}=$ constante de decaimento $\left(\operatorname{dia}^{-1}\right)$.

Estudos posteriores confirmaram a cinética básica de $1^{\text {a }}$ ordem (KLOCK, 1971; MARAIS, 1974; SHERRY; PARKER, 1979; YAÑEZ, 1993; CAVALCANTI, 2003) e estabeleceram ainda a influência da temperatura e da profundidade da lagoa sobre o valor da constante de decaimento. Propuseram uma equação tipo Arrhenius para descrever a influência da temperatura. A influência da profundidade também foi investigada por van Haandel e Lettinga (1994) e von Sperling (1999). As lagoas em todos esses estudos eram operadas com regime de fluxo contínuo. Com base nos trabalhos supracitados e em pesquisa própria, van Haandel e van der Lubbe (2019) propuseram uma equação geral para o valor da constante de decaimento de CTT em lagoas de polimento de fluxo contínuo em função da temperatura e profundidade (Eq. 2):

$k_{b}=\left(\frac{1,36}{H}\right) \cdot 1,07^{T-20}$

Em que:
$\mathrm{K}_{\mathrm{b}}=$ constante de decaimento $\left(\right.$ dia $\left.^{-1}\right)$;

$\mathrm{H}=$ profundidade da lagoa de polimento $(\mathrm{m})$;

$\mathrm{T}=$ temperatura $\left({ }^{\circ} \mathrm{C}\right)$.

Outro aspecto importante do decaimento dos CTT é o regime hidrodinâmico nas lagoas de polimento. De acordo com Levenspiel (1999), podem-se distinguir três situações em uma lagoa: (1) mistura completa; (2) sem mistura (fluxo pistão) e (3) fluxo disperso. Na prática, a mistura numa lagoa sempre será parcial, mas, dependendo das condições do regime de escoamento, pode se aproximar da de mistura completa ou sem mistura, onde o decaimento bacteriano é mais favorecido. As equações que definem a eficiência da remoção nessas condições podem ser derivadas da equação básica (Eq. 1) e são as seguintes:

a) Mistura completa (MARAIS; SHAW, 1961):

$\frac{N_{e}}{N_{i}}=\frac{1}{\left(1+k_{b} R_{h}\right)}$

Em que:

$\mathrm{N}_{\mathrm{e}}$ = concentração de CTT no efluente (UFC/100mL);

$\mathrm{N}_{\mathrm{i}}$ = concentração de CTT no afluente (UFC/100mL);

$\mathrm{k}_{\mathrm{b}}=$ constante de decaimento $\left(\mathrm{dia}^{-1}\right)$;

$\mathrm{R}_{\mathrm{h}}=$ tempo de permanência do líquido na lagoa (dia).

b) Série de mistura completa (MARAIS, 1974):

$\frac{N_{e}}{N_{i}}=\frac{1}{\left(1+k_{b} \cdot \frac{R_{h}}{M}\right)^{M}}$

Em que:

$\mathrm{N}_{\mathrm{e}}$ = concentração de CTT no efluente (UFC/100mL);

$\mathrm{N}_{\mathrm{i}}$ = concentração de CTT no afluente (UFC/100mL);

$\mathrm{k}_{\mathrm{b}}=$ constante de decaimento $\left(\mathrm{dia}^{-1}\right)$;

$\mathrm{R}_{\mathrm{h}}=$ tempo de permanência do líquido na lagoa (dia);

$M=$ número de lagoas em série (tamanhos iguais) (-).

c) Mistura parcial (WEHNER; WILHELM, 1956):

$\frac{N_{e}}{N_{i}}=\frac{4 a \cdot e^{1 / 2 D}}{(1+a)^{2} \cdot e^{a / 2 D}-(1-a)^{2} \cdot e^{-a / 2 D}}$ 
Em que:

$\mathrm{N}_{\mathrm{e}}$ = concentração de CTT no efluente (UFC/100mL); $\mathrm{N}_{\mathrm{i}}$ = concentração de CTT no afluente (UFC/100mL); $\mathrm{a}=\sqrt{1+4 k_{b} R_{h} D}$;

$\mathrm{D}=$ número de dispersão (-).

d) Sem mistura (LEVENSPIEL, 2003)

$\frac{N_{e}}{N_{i}}=e^{-k_{b} R_{h}}$

Em que:

$\mathrm{N}_{\mathrm{e}}$ = concentração de CTT no efluente (UFC/100mL); $\mathrm{N}_{\mathrm{i}}=$ concentração de CTT no afluente (UFC/100mL);

$\mathrm{k}_{\mathrm{b}}=$ constante de decaimento $\left(\mathrm{dia}^{-1}\right)$;

$\mathrm{R}_{\mathrm{h}}=$ tempo de permanência do líquido na lagoa (dia).

Pode-se notar que em todas as equações aparece o grupo adimensional $k_{b} R_{h}$. A Fig. 1 relaciona, em escala semi-logarítmica, a eficiência de remoção bacteriana (\%) em função do grupo $k_{b} R_{h}$ para diferentes configurações de lagoas: (1) uma lagoa de mistura completa; (2) séries de lagoas de mistura completa com 2 e 5 lagoas (de igual tamanho); e (3) uma lagoa sem mistura, que pode ser uma lagoa operando em fluxo em pistão ou em regime de batelada. Verifica-se uma diferença considerável entre a eficiência dos diferentes regimes de mistura, evidenciando que reatores sem mistura são mais eficientes e a diferença se torna maior na medida em que o valor de $k_{b} R_{h}$ se eleva.

Na Fig. 1 também é possível observar a eficiência de remoção bacteriana necessária para produzir um efluente adequado para uso em irrigação sem restrições. A concentração de CTT em esgoto municipal geralmente é da ordem de $10^{8} \mathrm{NMP} / 100 \mathrm{~mL}$ e, após tratamento anaeróbio em reator UASB, esse valor se reduz sensivelmente para $10^{7} \mathrm{NMP} / 100 \mathrm{~mL}$. Assim sendo, para ter um efluente final com qualidade para irrigação irrestrita, ou seja, com $10^{3} \mathrm{NMP} / 100 \mathrm{~mL}$, de cada 10.000 CTT pelo menos 9.999 CTT precisam ser removidos, ou seja, a eficiência de decaimento na lagoa de pós-tratamento tem de ser no mínimo de 99,99\%.
$\mathrm{Na}$ Fig. 2, observam-se valores de eficiência de reatores parcialmente misturados para diferentes valores do número de dispersão (D) em função de $k_{b} R_{h}$ a fim de analisar o efeito da intensidade de mistura no decaimento bacteriano. Ressalta-se que a intensidade da mistura na equação de Wehner e Wilhelm (3c) é representada pelo número de dispersão, tendo-se $D=0$ (sem mistura), $D=0,01$ (pouca mistura), $D=0,1$ (mistura moderada), $\mathrm{D}=1$ (mistura intensa) e $\mathrm{D}=\infty$ (mistura completa).

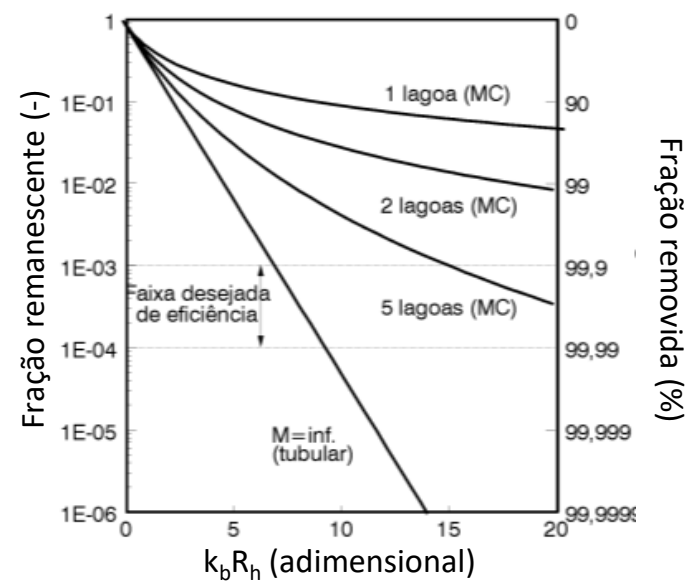

Figura 1 - Eficiência de remoção dos CTT em lagoas de diferentes configurações: Mistura completa (MC), séries de $\mathrm{MC}$ com 2 e 5 unidades e lagoa sem mistura em função de $k_{b} R_{h}$.

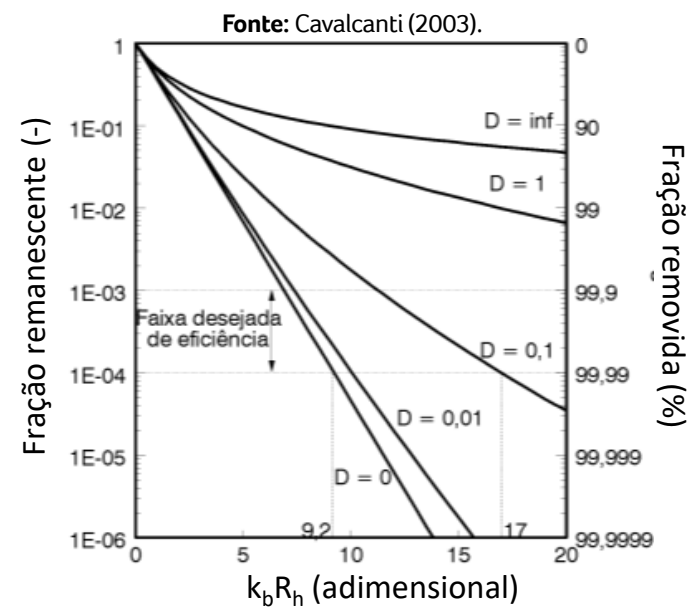

Figura 2 - Eficiência de remoção dos CTT em lagoas com mistura parcial para diferentes valores do número de dispersão $D$ em função $k_{b} R_{h}$. Fonte: Cavalcanti (2003). 
Yañez (1993), avaliando lagoas em escala real na América Latina, e von Sperling (1999), analisando especificamente lagoas no Brasil, chegaram à conclusão de que na prática a mistura em lagoas de estabilização de fluxo contínuo é considerável, com números de dispersão na faixa de 0,2 a 0,5. Portanto, nessas lagoas o decaimento de CTT é muito menor do que a taxa máxima que haveria em lagoas sem mistura. Todavia, a mistura é um aspecto essencial no funcionamento de lagoas de estabilização. $\mathrm{Na}$ verdade, a mistura é necessária para não criar desequilíbrio na lagoa entre a taxa de produção de oxigênio pela fotossíntese e a taxa de consumo de oxigênio para oxidação do material orgânico.

A mistura em lagoas diminui quando se constroem unidades rasas e com uma elevada proporção comprimento/largura (AGUNWAMBA et al., 1992; YAÑEZ, 1993; VON SPERLING, 1999), inclusive lagoas subdivididas em seções, com uso de divisórias internas (chicanas) (CAVALCANTI et al., 2001). Entretanto, pesquisas mostram que, em lagoas em escala real operando em regime de fluxo contínuo, a mistura se torna inevitável, mesmo quando se tem uma razão elevada entre o comprimento e a largura da lagoa (CAVALCANTI, 2003).

Santos e van Haandel (2021) mostraram que é factível operar lagoas de polimento em regime de bateladas quando o pré-tratamento é eficiente, por exemplo, pela aplicação do reator UASB. Nessas condições, o tempo de permanência do efluente na lagoa de polimento pode ser reduzido porque a taxa de decaimento em lagoas de bateladas sequenciais é muito maior do que em lagoas de fluxo contínuo sob condições comparáveis.

Nesse contexto, o presente estudo objetivou desenvolver expressões para determinar o valor da constante de decaimento, em termos de $E$. coli, em lagoas de polimento operando em regime de bateladas sequenciais em função da profundidade da lagoa e da temperatura, submetidas a condições semelhantes de radiação solar, bem como avaliar a influência do regime hidráulico sobre a eficiência da remoção bacteriana visando estimar o tempo de permanência necessário para obter um efluente com qualidade higiênica necessária, em termos de E.coli, para ser utilizado na irrigação irrestrita.

\section{METOdOLOGIA}

Buscou-se avaliar se a cinética de decaimento de bactérias do grupo Coliformes em lagoas de polimento operadas em bateladas sequenciais poderia ser descrita de acordo com a equação básica de Marais e Shaw (1961) (Eq. 1), bem como determinar expressões para a constante de decaimento em função da profundidade e temperatura.

O decaimento bacteriano, em termos de Escherichia Coli (E. Coli), foi avaliado em 06 lagoas de polimento operando em bateladas sequenciais (LPBS), com profundidades variando entre $0,2 \mathrm{~m}$ e $2,8 \mathrm{~m}(0,2 \mathrm{~m}, 0,4 \mathrm{~m}, 0,6 \mathrm{~m}, 1,0 \mathrm{~m}, 1,8 \mathrm{~m}$ e $2,8 \mathrm{~m})$. Nas lagoas com menos de $1 \mathrm{~m}$ de profundidade foi utilizado um agitador mecânico de baixa rotação $(6 \mathrm{rpm})$ que acionava uma palheta superficial a fim de proporcionar uma agitação suave para evitar a formação de algas flotadas.

As unidades de tratamento de esgoto foram instaladas na Estação Experimental de Tratamento Biológico de Esgotos Sanitários (Extrabes), da Universidade Federal de Campina Grande (UFCG) e da Universidade Estadual da Paraíba (UEPB), localizada no bairro do Catolé em Campina Grande. $O$ afluente das lagoas correspondeu ao efluente proveniente de um reator UASB com configuração modificada (Santos et al., 2016), com capacidade de 2,5 $\mathrm{m}^{3}$ e projetado para operar em um TDH de 6 horas, com vazão de $10 \mathrm{~m}^{3} / \mathrm{d}$, sendo alimentado com o esgoto proveniente do município de Campina Grande-PB. A temperatura durante os testes oscilou entre 24 e $26^{\circ} \mathrm{C}$.

$\mathrm{Na}$ realização das análises microbiológicas, as amostras foram coletadas em sacos estéreis de 100 
$\mathrm{mL}$, do tipo Whirl-Pak (Nasco, Fort Atkinson, WI) e, em seguida, transportadas, sob condições de refrigeração, para o Laboratório de Microbiologia Ambiental do Instituto Nacional do Semiárido (INSA). A determinação de $E$. coli foi feita por meio da técnica Colilert ${ }^{\circledR}$, utilizando a tecnologia do substrato definido (TSD), de acordo com metodologia descrita no Standard Methods for the Examination of Water and Wastewater (APHA; AWWA; WEF, 2017). Os resultados das quantificações foram apresentados em termos de número mais provável (NMP) por $100 \mathrm{~mL}$.

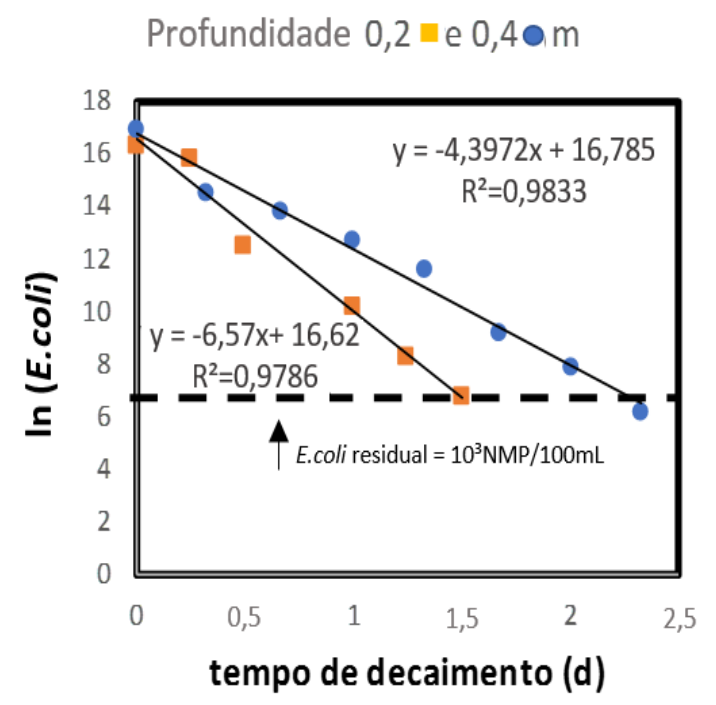

\section{RESULTADOS E DISCUSSÃO}

$\mathrm{Na}$ Fig. 3, pode-se observar o valor da concentração de E. coli em função do tempo nas diferentes profundidades de lagoas operando em regime de bateladas e tratando o efluente do reator UASB. É possível verificar que para todas as profundidades analisadas é válida a suposição básica de que o decaimento é um processo de primeira ordem: a relação no diagrama semi-log tem uma tendência de linearidade, embora a dispersão dos dados seja considerável $\left(R^{2} \approx 0,9\right)$.
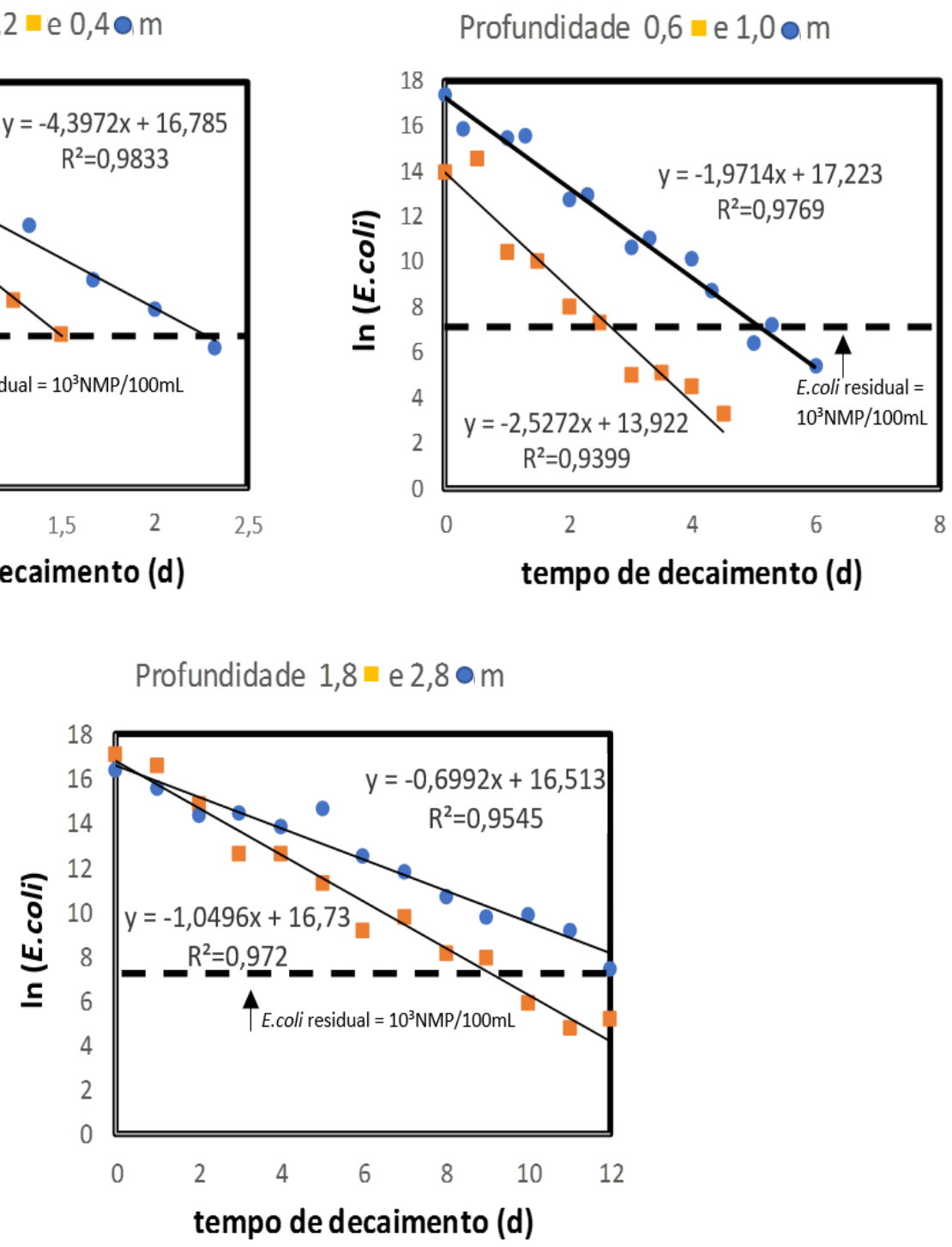

Figura 3 - Número de E. Coli por $100 \mathrm{~mL}$ de efluente do reator UASB tratado em lagoas com diferentes profundidades em função do tempo de decaimento nas bateladas (escala semi-logarítmica). 
Os dados apresentados na Fig. 3 mostram também que o valor da constante de decaimento, que corresponde ao valor da inclinação da reta, varia consideravelmente de acordo com a profundidade. Uma melhor visualização da influência da profundidade sobre o valor da constante de decaimento pode ser analisada na Fig. 4, que relaciona os valores das constantes de decaimento, obtidas pelas retas da Fig. 3, com as profundidades das lagoas. É possível notar que a tendência é uma relação hiperbólica que pode ser descrita da seguinte forma (Eq. 4):

$k_{b 25}=\frac{1,6}{H}$

Em que: $\mathrm{k}_{\mathrm{b} 25}=$ constante de decaimento bacteriano a $25^{\circ} \mathrm{C} ; \mathrm{H}=$ profundidade da lagoa de polimento $(\mathrm{m})$.

A influência da temperatura no decaimento bacteriano pode ser descrita pela Equação de Arrhenius (Eq. 5), considerando o valor de $k_{b}$ à temperatura de $20^{\circ} \mathrm{C}$.

$k_{b T}=k_{b 20} \cdot \theta^{T-20}$

Em que:

$\mathrm{k}_{\mathrm{bT}}=$ constante de decaimento para uma determinada temperatura $\left(\mathrm{dia}^{-1}\right)$;

$\mathrm{k}_{\mathrm{b} 20}=$ constante de decaimento à temperatura de $20^{\circ} \mathrm{C}\left(\mathrm{dia}^{-1}\right)$;

$\theta=$ coeficiente determinado experimentalmente em função da temperatura (-).

Ao substituir a Eq. 4 na Eq. 5, obtém-se uma expressão geral para determinação do valor da constante de decaimento em função da profundidade e da temperatura. Adotando o coeficiente de Arrhenius $\theta=1,07$ (KLOCK, 1971; YANEZ, 1993), a expressão geral para a constante de decaimento fica da seguinte forma (Eq. 6):

$k_{b T}=\frac{1,14}{H} \cdot 1,07^{T-20}$

Observa-se que a Eq. 6 se assemelha à proposta de van Haandel e van der Lubbe (2019) apresentada na Eq. 2; entretanto, o valor resultante de $k_{b}$ no presente estudo é um pouco menor. Vale destacar ainda que a Eq. 6 é válida para condições semelhantes de radiação solar.

Pela Fig. 4 e pela Eq. 6, pode-se verificar ainda que o valor da constante de decaimento é inversamente proporcional à profundidade das lagoas. Sabe-se ainda que o tempo de permanência do efluente em uma lagoa é proporcional à profundidade da mesma (para uma determinada área), conforme pode ser visualizado na Fig. 3. Sendo assim, é possível concluir que lagoas mais profundas podem alcançar as mesmas eficiências que lagoas mais rasas em tempo de detenção maior. Isso ocorre porque, quando a profundidade aumenta, os menores valores das constantes de decaimento podem ser compensados pelo maior tempo de permanência do efluente na lagoa. Apesar de a radiação solar e tempo de exposição ser um dos principais fatores da desinfecção em lagoas de polimento, em especial nas menores profundidades, outros mecanismos e processos podem também contribuir para a remoção bacteriana, inclusive nas camadas mais inferiores das unidades, onde a incidência da radiação é mínima ou inexistente, tais como predação, competição, sedimentação, concentrações de constituintes, $\mathrm{pH}$ etc. (DIAS; PASSOS; VON SPERLING, 2017).

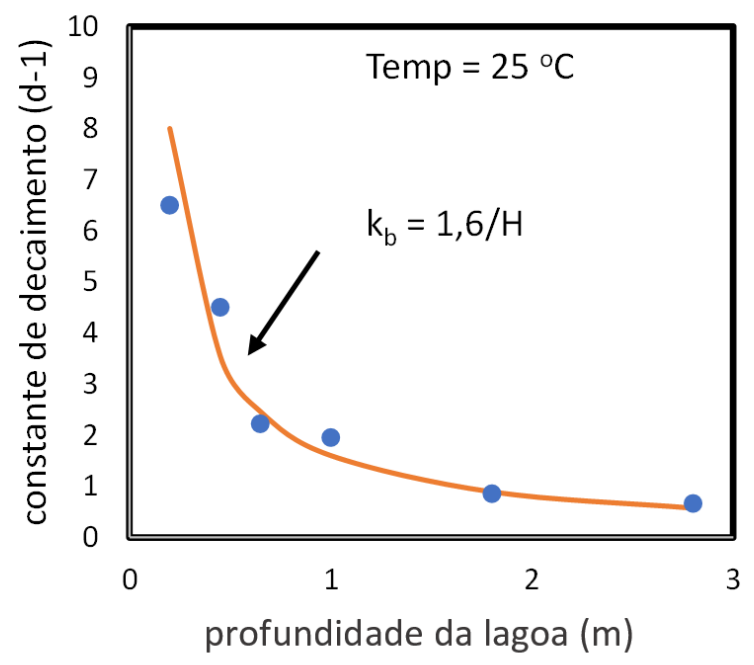

Figura 4 - Relação entre a constante de decaimento e a profundidade em lagoas de polimento em regime de bateladas sequenciais. 


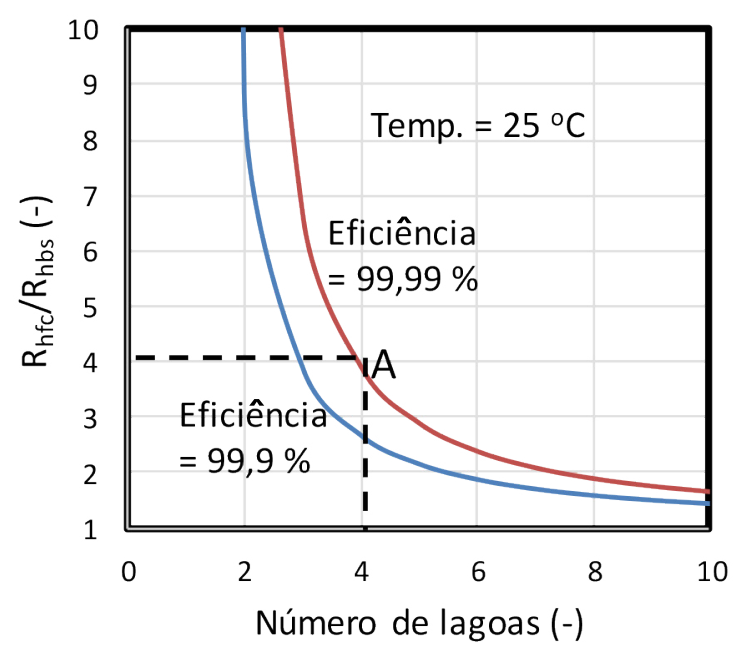

Figura 5 - Razão entre o tempo de permanência de lagoas de polimento de fluxo contínuo (LPFC) em série e de bateladas sequenciais (LPBS) para a remoção bacteriana de 99,9 e $99,99 \%$.

O decaimento bacteriano depende também do regime hidráulico que se aplica na lagoa. Na Fig. 5 , pode-se observar a diferença do decaimento entre o regime de fluxo contínuo e o de bateladas sequenciais. Nessa figura plotou-se a razão entre o tempo de permanência em lagoas de fluxo contínuo e em bateladas sequenciais $\left(R_{h f c} / R_{h b s}\right)$ em função do número $M$ de lagoas de fluxo contínuo em série. Os valores de $R_{\mathrm{hfc}}$ (fluxo contínuo) utilizados na Fig. 5 foram obtidos a partir da pesquisa anterior realizada por Cavalcanti (2003), também nas dependências da Extrabes, em Campina Grande/PB. A relação $\left(R_{h f c} / R_{h b s}\right)$ foi calculada da seguinte maneira:

\section{a) Lagoas de polimento em fluxo contínuo (LPFC)}

Para uma quantidade de $M$ lagoas iguais em série, a fração bacteriana remanescente se expressa como:

$$
1-E_{f c}=\frac{N_{e}}{N_{i}}=\frac{1}{\left(1+k_{b} \cdot \frac{R_{h f c}}{M}\right)^{M}}
$$

Portanto, o grupo adimensional $k_{b} R_{h f c}$ pode ser expresso como:

$$
k_{b} R_{h f c}=\mathrm{M}\left(\left(\frac{1}{1-E_{f c}}\right)^{1 / M}-1\right)
$$

Em que:

$E_{f_{c}}=$ Eficiência de remoção bacteriana nas $\operatorname{LPFC~(-);~}$

$\mathrm{N}_{\mathrm{e}}=$ concentração de $E$.colino efluente $(\mathrm{NMP} / 100 \mathrm{~mL})$;

$\mathrm{N}_{\mathrm{i}}=$ concentração de $E$.colino afluente $(\mathrm{NMP} / 100 \mathrm{~mL})$;

$\mathrm{k}_{\mathrm{b}}=$ constante de decaimento $\left(\mathrm{dia}^{-1}\right)$;

$\mathrm{R}_{\mathrm{hfc}}=$ tempo de permanência do líquido nas LPFC (dia);

$M=$ número de lagoas em série (tamanhos iguais) (adimensional).

\section{b) Lagoas de polimento em bateladas sequen- ciais (LPBS)}

Por outro lado, em uma lagoa de bateladas sequenciais, a fração bacteriana remanescente é expressa como:

$1-E_{b s}=\frac{N_{e}}{N_{i}}=e^{-k_{b} R_{h b s}}$

Portanto, o grupo adimensional $k_{b} R_{h f c}$ pode ser expresso como:

$k_{b} R_{h b s}=\ln \left(\frac{1}{1-E_{b s}}\right)$

Em que:

$\mathrm{E}_{\mathrm{bs}}=$ Eficiência de remoção bacteriana nas LPBS (-);

$\mathrm{N}_{\mathrm{e}}$ = concentração de $E$.colino efluente (NMP/100mL);

$\mathrm{N}_{\mathrm{i}}=$ concentração de $E$.colino afluente $(\mathrm{NMP} / 100 \mathrm{~mL})$;

$\mathrm{k}_{\mathrm{b}}=$ constante de decaimento $\left(\mathrm{dia}^{-1}\right)$;

$\mathrm{R}_{\mathrm{hbs}}=$ tempo de permanência do líquido nas LPBS (dia).

Sendo assim, para uma eficiência de $\mathrm{E}_{99,9}=0,999$ ou $99,9 \%$ (ou seja, $E_{f_{c}}=E_{b s}=0,001$ ), a proporção do tempo de permanência na série de lagoas de fluxo contínuo e na lagoa de bateladas sequenciais é dada pela Eq. 9a. 


$$
\frac{R_{h f c}}{R_{h b s}}=\mathrm{M}\left(\left(\frac{1}{1-E_{f c}}\right)^{1 / M}-1\right) / \ln \left(\frac{1}{1-E_{b s}}\right)=M\left((1000)^{1 / M}-1\right) / 6,9
$$

Semelhantemente, para uma eficiência de 99,99\% (ou seja, Efc = Ebs = 0,0001) tem-se:

$$
\frac{R_{h f c}}{R_{h b s}}=\mathrm{M}\left(\left(\frac{1}{1-E_{f c}}\right)^{1 / M}-1\right) / \ln \left(\frac{1}{1-E_{b s}}\right)=M\left((1000)^{1 / M}-1\right) / 9,2
$$

Em que:

$\mathrm{E}_{\mathrm{bs}}=$ Eficiência de remoção bacteriana nas LPBS (-);

$\mathrm{E}_{\mathrm{fc}}=$ Eficiência de remoção bacteriana nas LPFC (-);

$\mathrm{N}_{\mathrm{e}}$ = concentração de E.colino efluente (NMP/100mL);

$\mathrm{N}_{\mathrm{i}}=$ concentração de E.colino afluente (NMP/100mL);

$\mathrm{R}_{\mathrm{hbs}}=$ tempo de permanência do líquido nas LPBS (dia);

$\mathrm{R}_{\mathrm{hfc}}=$ tempo de permanência do líquido nas LPFC (dia).

A Fig. 5 mostra a proporção para uma eficiência de 99,9 e 99,99\% que, na prática, geralmente é a faixa desejada de eficiência. Como o número de lagoas em série de fluxo contínuo normalmente é da ordem de 2 a 4, a diferença entre os valores de $R_{h f c}$ e $R_{h b}$ s é considerável. Por exemplo, observando a Fig. 5 para uma eficiência de 99,99\% e uma série de 4 lagoas de fluxo contínuo, a proporção $\mathrm{R}_{\mathrm{hfc}} / \mathrm{R}_{\mathrm{hbs}}$ é de 4 , indicando que o tempo de permanência da série de lagoas de fluxo contínuo é 4 vezes maior que o da lagoa de bateladas sequenciais. Isso significa que cada lagoa da série de 4 de fluxo contínuo tem que ter o mesmo tempo de permanência (ou mesmo volume ou dimensões) que a lagoa de bateladas sequenciais. A Fig. 5 mostra claramente que o tempo de permanência em lagoas de bateladas sequenciais é muito menor que em lagoas de fluxo contínuo. Portanto, é grande a vantagem usar o regime de bateladas sequenciais.

O tempo de permanência do efluente para que ocorra o decaimento bacteriano para a faixa desejada $(99,9 \%$ a $99,99 \%)$ em lagoas de polimento de bateladas sequenciais é consideravelmente menor que em lagoas de fluxo contínuo. Por ou- tro lado, esse tempo continua sendo bem maior, principalmente em lagoas mais profundas, que o tempo necessário para remoção de ovos de helmintos reportado na literatura, que é em torno de 3 dias (SAQQQAR; PESCOD, 1991; AYRES et al., 1992). Além disso, o decaimento bacteriano é bem mais lento que a remoção de material orgânico em lagoas de bateladas sequenciais (CAVALCANTI, 2003). Sendo assim, a remoção de $E$. coli constitui fator determinante no dimensionamento de lagoas de bateladas sequenciais quando o interesse não é a redução nas concentrações de nutrientes, mas sim a produção de um efluente com qualidade higiênica adequada para irrigação irrestrita

\section{CONCLUSÕES}

Em boa aproximação, observou-se que o decaimento do número de $E$. coli em lagoas de polimento de bateladas sequenciais ocorre de acordo com um processo de primeira ordem, isto é, a taxa de decaimento é proporcional a sua concentração a qualquer momento.

A constante de decaimento depende da profundidade da lagoa. Os dados experimentais sugerem que o valor da constante é inversamente proporcional à profundidade.

Como o tempo de permanência é proporcional à profundidade e a taxa de decaimento é inversamente proporcional à profundidade, a eficiência 
de uma lagoa depende somente da razão vazão/ área e não da profundidade.

Pelo fato do decaimento bacteriano ser um processo de primeira ordem, lagoas em regime de bateladas sequenciais têm uma vantagem considerável sobre as lagoas de fluxo contínuo, podendo produzir em uma área muito menor um efluente de qualidade higiênica que permite o seu uso para irrigação sem restrições.

\section{AGRADECIMENTOS}

Os autores agradecem ao Instituto Nacional do Semiárido (INSA) pelo apoio para realização das análises microbiológicas, e ao Conselho Nacional de Desenvolvimento Científico e Tecnológico (CNPq) pelo incentivo financeiro as pesquisas.

\section{CONTRIBUIÇÃO DOS AUTORES}

Todos os autores contribuíram de forma igualitária.

\section{REFERÊNCIAS}

AGUNWAMBA, J. C.; EGBUNIWE, N.; ADEMILUYI, J. O. Prediction of the dispersion number in waste stabilization ponds. Water Research, London, v. 26, n. 1, p. 85-89, 1992. https://doi. org/10.1016/0043-1354(92)90115-K

AMERICAN PUBLIC HEALTH ASSOCIATION - APHA; AMERICAN WATER WORKS ASSOCIATION - AWWA; WATER ENVIRONMENT ASSOCIATION - WEF. Standard methods for the examination of water \& wastewater. $23^{\text {st }}$ edition. Washington, 2017. 1360 p.

AYRES, R. M., ALABASTER, G. P., MARA, D. D., LEE, D. L. A design equation for human intestinal nematode egg removal in waste stabilization ponds. Water Research, v. 26, n. 6, p. 863-865, 1992. https://doi.org/10.1016/0043-1354(92)90019-Z

CAVALCANTI, P.F.F. Integrated application of the UASB reactor and ponds for domestic sewage treatment in tropical regions. Doctoral Thesis - Wageningen Agricultural University, Wageningen, The Netherlands, 2003. 141p.

CAVALCANTI, P. F. F; VAN HAANDEL, A; KATO, M T.;VON SPERLING, M. LUDUVICE, M. L.; MONTEGGIA, L O. Pós-Tratamento De Efluentes Anaeróbios Por Lagoas De Polimento. In: CHERNICHARO, C. A.
DE L. (Ed.). Pós-Tratamento de Efluente de Reatores Anaeróbios. Belo Horizonte: Projeto PROSAB, 2001.

CHICK, H. An investigation of the laws of disinfection. Journal of Hygiene, v. 8, n. 1, p. 92-158, 1908.

DIAS, D. F. C.; PASSOS, R. G.; VON SPERLING, M. A review of bacterial indicator disinfection mechanisms in waste stabilisation ponds. Reviews in Environmental Science and Biotechnology, v. 16, n. 3, p. 517-539, 2017.

HESPANHOL, I. Potencial de reúso de água no Brasil: agricultura, indústria, municípios, recarga de aquíferos. Revista Brasileira de Recursos Hídricos, Porto Alegre, ed. comemorativa, v.7, n.4, p.7597, 2002.

HETTIARACHCHI, H.; REZA ARDAKANIAN. Safe use of wastewater in agriculture: good practice examples. Dresden, Germany: United Nations University Institute for Integrated Management of Material Fluxes and of Resources (UNU-FLORES), 2016.

KLOCK, W. J. Survival of coliform bacteria in wastewater treatment lagoons. J. Water Pollution Control Federation, v. 43, n. 10, p. 2071-83, 1971

LEAL, R. M. P. et al. Agricultural utilization of treated sewage effluent: Experience from Brazil. Israel Journal of Plant Sciences, v. 59, n. 2-4, p. 235-248, 2011.

LEVENSPIEL, O. Chemical Reaction Engineering, 3rd Edition, 3rd edn. Wiley, New York, USA, 1999.

LIU, L.; HALL, G.; CHAMPAGNE, P. Disinfection processes and mechanisms in wastewater stabilization ponds: A review. Environmental Reviews, v. 26, n. 4, p. 417-429, 2018.

MARAIS, G.V.R. Fecal Bacteria Kinetics in stabilization ponds, Journal of the Environmental Engineering Division ASCE, v. 100 (EE1), n.1, 119-139, 1974.

MARAIS, G.V.R; SHAW, V.A. Rational theory for design of waste stabilization ponds in South Africa, Transactions of the South African. Institute of The Civil Engineering Engineer in South Africa, v. 3, n. 11, 205-227, 1961.

NELSON, K. L.; CISNEROS, B. J.; TCHOBANOGLOUS G, DARBY J L. Sludge accumulation, characteristics and pathogen inactivation in four primary waste stabilisation ponds in central Mexico. Water Research, v. 38, n. 1, p. 111-127, 2004. https://doi.org/10.1016/j. watres.2003.09.013

PEDRERO, F.; KALAVROUZIOTIS, I.; ALARCÓN, J. J.; KOUKOULAKIS, P.; ASANO, T. Use of treated municipal wastewater in irrigated agriculture-Review of some practices in Spain and Greece. Agricultural Water Management, v. 97, n. 9, p. 1233-1241, 2010. https://doi.org/10.1016/j.agwat.2010.03.003

SANTOS, S. L; MEDEIROS, S. S.; VAN HAANDEL A. C. Transformação de lagoas de estabilização: reengenharia de um sistema obsoleto de tratamento de águas residuárias. Revista DAE, edição especial, n. 229, Março, 2021. 
SAQQAR, M.M.; PESCOD, M.B. Microbiological performance of multi-stage stabilisation ponds for effluent use in agriculture, Water Science Technology, v. 23, ed. 7-9, 7-8p. 1517-1524, 1991. https://doi.org/10.2166/wst.1991.0605

SHERRY, G. P.; PARKER C. D. Development of an improved quantitative relationship between bacterial die off, design and operational factors for anaerobic, aerobic and maturation type lagoon systems. Progress in Water Technology, v. 11, n. (4/5), p. 427-443, 1979.

VAN HAANDEL, A. C.; LETTINGA, G. Anaerobic sewage treatment: a practical guide for regions with a hot climate. John Wiley and Sons, 1994, 222p.

VAN HAANDEL; VAN DER LUBBE. Anaerobic sewage treatment. IWA Publishing, Londres RU, 2019. 454p.
VON SPERLING, M. Performance evaluation e mathematical modelling of coliform die-off in tropical and subtropical waste stabilization ponds, Water Research, v. 33, n. 6, p. 1435-1448, 1999. https://doi.org/10.1016/S0043-1354(98)00331-5

WEHNER, J.F; WILHELM, R. H. Boundary conditions of continuous flow reactors. Chemical Engineering Science, v. 6, n. 289, p. 8993, 1956.

WORLD HEALTH ORGANIZATION. Guidelines for the safe use of wastewater, excreta and greywater: Policy and regulatory aspects. Geneva: United Nations Environment Programme, v.1, p.100, 2006.

YAÑEZ, F. Lagunas de estabilización. CEPIS, Lima, Peru, 1993. 